\title{
Enhancement of Anti-skin inflammatory Activities of Scutellaria baicalensis using an Alkaline Reduced Water Extraction Process
}

\author{
Wooseok Choi, Hee-Souk Kwon, and Hyeon Yong Lee
}

Received December 18, 2013; revised Arpil 1, 2014; accepted April 22, 2014; published online December 31, 2014

(C) KoSFoST and Springer 2014

\begin{abstract}
WE (water extraction at $100^{\circ} \mathrm{C}$ for $24 \mathrm{~h}$ ), EE $\left(70 \%\right.$ ethanol extraction at $80^{\circ} \mathrm{C}$ for $\left.24 \mathrm{~h}\right)$, and $\mathrm{AWE}$ (alkaline reduced water extraction at $100^{\circ} \mathrm{C}$ for $24 \mathrm{~h}$ ) were performed. Nitric oxide production from macrophages of AWE extracts at $1.0 \mathrm{mg} / \mathrm{mL}$ was decreased to $3.1 \mu \mathrm{mol}$. Secretion of $\mathrm{PGE}_{2}$ from human fibroblasts was also reduced to $496.47 \mathrm{pg} / \mathrm{mL}$ at $1.0 \mathrm{mg} / \mathrm{mL}$ of AWE extracts with UV irradiation. Anti-skin inflammatory activities were enhanced by extraction of $8.894 \mathrm{mg} / \mathrm{g}$ more baicalein, the major bioactive component in Scutellaria baicalensis, using alkaline reduced water (AWE), compared to 1.157 $\mathrm{mg} / \mathrm{g}$ for $\mathrm{WE}$ and $2.215 \mathrm{mg} / \mathrm{g}$ for EE. Improvement was caused by better and more elution of both hydrophobic and hydrophilic substances using alkaline reduced water and also by a synergistic effect between the antioxidant and anti-inflammatory activities of AWE extracts.
\end{abstract}

Keywords: Scutellaria baicalensis, baicalein, alkaline reduced water, anti-skin inflammatory activity, antioxidative activity

\section{Introduction}

Scutellaria baicalensis is the root of a perennial herbaceous plant from the Labiatae family that originates from China.

\footnotetext{
Wooseok Choi

Department of Medical Biomaterials Engineering, Kangwon National University, Chuncheon, Gangwon 200-701, Korea

Hee-Souk Kwon

Hankook Cosmo Cosmetics Co., Bucheon, Gyeonggi 421-808, Korea

Hyeon Yong Lee $(\bowtie)$

Department of Food Science and Engineering, Seowon University, Cheongju, Chungbuk 361-742, Korea

Tel, Fax: +82-43-299-8471

E-mail: hyeonl@seowon.ac.kr
}

This root has been introduced to Korea as a medicinal plant, and is now cultivated nationwide (1). The main components of $S$. baicalensis, (baicalin, baicalein, and wogonin) are widely used in traditional herbal medicine for anti-skin inflammatory activity. This root is known to have anti-inflammatory, anti-pyretic, anti-bacterial and diuretic effects (2-6). The main ingredients of $S$. baicalensis, including baicalin and baicalein, are fat-soluble substances. Thus, ethanol and other organic solvents must be used for extraction. However, organic substances, such as ethanol, are not desired in cosmetic development. This has lead to recent interest in water, and research on functional water with different manufacturing and treatment methods has increased (7).

As a solution for effective $S$. baicalensis extraction, alkaline reduced water, which differs from normal water, is a functional type of water that is known as 'Water of the Wonder' (8). Alkaline reduced water was first made in Japan for drinking. Functional water includes electrolyzed alkaline reduced water, acidic water, and ionic water. The uses of functional water vary based on characteristics, and functional water is also used for sterilization and disinfection. Alkaline reduced water can be manufactured using different methods, the most common being electrolysis. It was reported that the minerals generated at the negative electrolytic pole cause the structure of electrolyzed alkaline reduced water to become hexagonal, which provides greater strength (8). This structure allows water to easily deliver hydrogen, the active component, by penetrating cells or other micro-substances, and the hexagonal structure facilitates absorption and excretion of substances. Additionally, alkaline reduced water has a higher oxygen content than other functional waters and contains a small amount of the essential minerals necessary for living organisms and stimulation of metabolism (9).

The effects of alkaline reduced water include elimination 
of free radicals due to the strong reducing power of the hydrogen that is generated in the water using an electric device, an improvement in hyperlipidemia, and an atopic dermatitis effect $(7,8,10)$. This water is also used for hydrotherapy to eliminate the free radicals that accelerate oxidation. Thus, hydrotherapy is an auxiliary method for treating diseases. Alkaline reduced water is frequently used to treat chronic disease (11).

The distinguishing characteristics of alkaline reduced water include size of water clusters (or water molecule groups) of $54-60 \mathrm{~Hz}$ (the unit of water clusters). This is tiny size of water clusters were absorbed in the body. In general, one cluster has a group of 10-16 water molecules. This cluster size of alkaline water is smaller than the 280 $\mathrm{Hz}$ size of acidic water, and also smaller than the sizes of general distilled water $(100 \mathrm{~Hz})$, rain water $(118 \mathrm{~Hz})$, and even mineral water $(94 \mathrm{~Hz})(12)$. Therefore, the small size of alkaline water facilitates absorption, extraction, and dissolution through rigid plant cell walls of $S$. baicalensis, or other natural substances (13). Additionally, permeation is also easier for alkaline reduced water than for regular distilled water because the smaller cluster size has less surface tension and can penetrate dehydrated body tissues more effectively. Therefore, alkaline reduced water can increase both the efficiency of extraction and the capacity to break down lipids and fatty acids, such as cholesterol $(14,15)$. A previous study on alkaline reduced water demonstrated an anti-skin inflammatory effect, including atopic dermatitis effects (8). Therefore, extraction of both water-soluble and fat-soluble substances may be possible (16). Therefore, in this work, alkaline reduced water was used as an extraction solvent to improve extraction of biologically active substances from $S$. baicalensis. An increase in anti-skin inflammatory activities was obtained.

\section{Materials and Methods}

Cell cultures and sample preparation The cell lines used were mouse macrophage RAW 264.7 cells (KCLB 40071; Korean Cell Line Bank, Seoul, Korea) and human fibroblast CCD-986sk cells (KCLB 21947; Korean Cell Line Bank). Media used for culturing cells were RPMI 1640 (Gibco; Bend, OR, USA), gentamycin sulfate (G1914; Sigma, St. Louis, MO, USA), and HEPES buffer (90909C; Sigma) enriched with 10\% fetal bovine serum (FBS; Gibco). S. baicalensis was purchased at Daegwang Pharmacy (Chuncheon, Korea) and was ground to a size of 2-3 mm using a grinder (HMF-1000A; Hanil Electric, Seoul, Korea) before use. Alkaline water for extraction was generated at the negative terminal during electrolysis (AK8000; Nexus Co., Incheon, Korea). The amount of alkaline reduced water used for the process was $10 \mathrm{x}$ the weight of ground $S$. baicalensis. Hot water extraction was performed at $100^{\circ} \mathrm{C}$ for $24 \mathrm{~h}$ using alkaline reduced water or distilled water (W0003; Samchun Pure Chemical Co., Pyeongtaek, Korea), and at $80^{\circ} \mathrm{C}$ for $24 \mathrm{~h}$ using ethanol (02860; Sigma). Obtained extracts were filtered through $20-25 \mu \mathrm{m}$ filter paper (Whatman, Fairfield, CT, USA), then condensed using a rotary vacuum evaporator (Rotary Vacuum Evaporator N-N series; Eyela, Tokyo, Japan). Extracts were freeze dried using a lyophilizer (TFD series; IIShinBioBase, Dongduchun, Korea) before use (17).

Measurement of cell toxicity Cell cytotoxicity was measured using the MTT method (18). Human fibroblast CCD-986sk cells (KCLB 21947; Korean Cell Line Bank) that were cultured at $1.0 \times 10^{6}$ cells/well in 96-well plate (353274 384; BD FALCON, Colorado Springs, CO, USA), and cultured for $24 \mathrm{~h}$. Then, extracts of $S$. baicalensis from alkaline reduced water extraction or $70 \%$ ethanol extraction were injected into each well at different concentrations $(0.2-1.0 \mathrm{mg} / \mathrm{mL})$, and cells were cultured in a $\mathrm{CO}_{2}$ incubator (CB150; Binder, Tuttlingen, Germany) for $24 \mathrm{~h}$. MTT solution (88417; Sigma) at a concentration of $5 \mu \mathrm{g} / \mathrm{mL}$ was added to each well, and the supernatant was reduced after $4 \mathrm{~h}$. Then, $10 \mu \mathrm{L}$ of acid-isopropanol $(0.04 \mathrm{~N}$ $\mathrm{HCl}$ in isopropanol, W292907; Sigma) was added to each well, and the absorbance was measured at $565 \mathrm{~nm}$ using a microplate reader (M1000 PRO; Infinite, Mannedorf, Switzerland).

Measurement of antioxidant activities The DPPH radical scavenging activity was measured using a modified Dietz assay (19). First, $80 \mu \mathrm{L}$ of each sample $\left(100^{\circ} \mathrm{C} S\right.$. baicalensis hot water, $80^{\circ} \mathrm{C} \mathrm{S}$. baicalensis ethanol, and $100^{\circ} \mathrm{C}$ S. baicalensis alkaline reduced water extracts), ascorbic acid (1043003, 465119; Sigma), and baicalein (465119; Sigma), which is an indicator of $S$. baicalensis activity, were mixed with $200 \mu \mathrm{L}$ of $0.1 \mathrm{mM} \mathrm{DPPH}$ (dissolved in ethanol, D9132; Sigma) and the extraction solvent $(0.5 \mathrm{mg} / \mathrm{mL})$ in a 96-well plate $(353274384$; BD FALCON). The mixture was left in a dark room for $20 \mathrm{~min}$ at $25^{\circ} \mathrm{C}$. The absorbance of the mixture was measured at a wavelength of $525 \mathrm{~nm}$ using a microplate reader (EMax Endpoint ELISA Microplate Reader, Sunnyvale, CA, USA). The result was calculated using the DPPH radical scavenging activity (\%) equation as:

$$
\begin{aligned}
& \text { DDPH radical scavenging activity (\%) } \\
& =\frac{\text { control OD }- \text { sample OD }}{\text { control OD }} \times 100
\end{aligned}
$$

Measurement of nitric oxide (NO) production Measurement was performed using a modified Green assay with mouse macrophage RAW264.7 cells (20). First, 1.0× 
$10^{6}$ cells $/ \mathrm{mL}$ were placed into a 96-well plate $(353274384$; BD FALCON) with RPMI 1640 (31800022; Gibco) containing $100 \mathrm{U} / \mathrm{mL}$ of penicillin (A1593; Sigma), $100 \mu \mathrm{g} / \mathrm{mL}$ of streptomycin (85886; Sigma), and $10 \%$ (v/ v) FBS (10437028; Gibco). Macrophages were then cultured for $2 \mathrm{~h}$. $S$. baicalensis alkaline reduced water, $S$. baicalensis ethanol, and $S$. baicalensis hot water extracts at different concentrations $(0.2-1.0 \mathrm{mg} / \mathrm{mL})$ were inoculated into the cultured cells, which were then cultured for an additional $1 \mathrm{~h}$. Afterwards, LPS ( $1 \mu \mathrm{g} / \mathrm{mL}, \mathrm{L} 2630$; Sigma) was added to this mixture, followed by culturing at $37^{\circ} \mathrm{C}$ and $5 \% \mathrm{CO}_{2}$ in an incubator (CB150; Binder) for $24 \mathrm{~h}$. When culturing the cells, the amount of $\mathrm{NO}$ generated was measured and used as a control. Resveratrol (R5010; Sigma) was used as a positive control, and baicalein (465119; Sigma) was used as a standard. Then, $50 \mu \mathrm{L}$ of the cell culture supernatant was obtained using centrifugal separator (Combi 514R; Hanil Science Medical., Daejeon, Korea) and allowed to react with $50 \mu \mathrm{L}$ of Griess reagent (G4410; Sigma) for $5 \mathrm{~min}$ before the absorbance of the mixture was measured at $540 \mathrm{~nm}$ using a microplate reader (EMax). $\mathrm{NaNO}_{2}$ (35273; Sigma) was used as a standard.

Measurement of prostaglandin $\mathrm{E}_{2}\left(\mathrm{PGE}_{2}\right)$ production Production of $\mathrm{PGE}_{2}$ was measured using a CorrelateEIA $^{\mathrm{TM}}$ Prostaglandin $\mathrm{E}_{2}$ kit Assay (R\&D Systems Inc., Minneapolis, MN, USA). Approximately $5.0 \times 10^{5}$ cells $/ \mathrm{mL}$ of mouse macrophage RAW264.7 cells (KCLB 40071; Korean Cell Line Bank) was incubated in a 96-well plate ( 353274384 ; BD FALCON) for $24 \mathrm{~h}$, then the cells were then treated with different concentrations $(0.2-1.0 \mathrm{mg} / \mathrm{mL})$. Afterwards, the mixtures were allowed to react for $4 \mathrm{~h}$, then $1 \mu \mathrm{g} / \mathrm{mL}$ of LPS (L2630; Sigma) was added before the macrophages were incubated at $37^{\circ} \mathrm{C}$ in $\mathrm{CO}_{2}$ in an incubator (CB150; Binder) for $18 \mathrm{~h}$. The medium from this incubation was used as a sample for an EIA kit (KGE004B; R\&D Systems Inc.) to measure the amount of $\mathrm{PGE}_{2}$.

HPLC analysis of extracts using different extraction solvents HPLC was used to compare the peak profiles of alkaline-reduced water, distilled water, and $70 \%$ ethanol extracts. Extracts and standards of $S$. baicalensis and baicalein were dissolved in methanol (34860; Sigma) for HPLC analysis at $100 \mathrm{ppm}$. The solutions were then filtered through a $0.2 \mu \mathrm{m}$ syringe filter (ALG422A; Gilson Scientific Ltd., Luton, UK). HPLC was performed using a Bio-Tek 500 series (BioTek; Winooski, VT, USA), a Bio-Tek 522 controller pump, a Bio-Tek HPLC 535 UV Detector (277 $\mathrm{nm}$ ), and a Prevail C18 column (Prevail C18 $5 \mu \mathrm{m} 4.6 \times 250$ mm, A-99301; Alltech, Nicholasville, KY, USA). Acetonitrile (34967; Sigma) (A) and triple distilled water (W0006; Samchun Pure Chemical Co.) (B) containing 1\% acetic acid (320099; Sigma) were used as the mobile phase at 1 $\mathrm{mg} / \mathrm{mL}$. Proportions of components during the gradient elution were $30 \% \mathrm{~A}$ and $70 \% \mathrm{~B}$ for $15 \mathrm{~min}, 65 \% \mathrm{~A}$ and $35 \% \mathrm{~B}$ for $25 \mathrm{~min}$, and $30 \% \mathrm{~A}$ and $70 \% \mathrm{~B}$ for $45 \mathrm{~min}(16)$.

Statistical analysis Statistical analysis was performed on data from 3 replicates. The mean value of test results was obtained using the SAS (Statistical Analysis System) program (SAS Institute, Cary, NC, USA) and statistical analysis was used to determine significant differences $(p<0.05)$.

\section{Results and Discussion}

Comparison of extraction yields using different solvents Extraction yields for distilled water, $70 \%$ ethanol, and alkaline reduced water are shown in Table 1 . The highest yield of $21.8 \%(\mathrm{w} / \mathrm{w})$ was obtained using electrolyzed alkaline reduced water. A yield of $20.3 \%$ was estimated for $70 \%$ ethanol, followed by $19.2 \%$ for hot distilled water extraction. This result was similar to results for fat-soluble substance extraction where increases from a minimum of $2 \%$ to a maximum of $5 \%$ with a non-polar solvent were reported (21), probably caused by the small cluster size of alkaline reduced water of $54-60 \mathrm{~Hz}$ that allowed the water to easily penetrate the cell wall $(13,21)$.

Use of natural substances extracted using alkaline reduced water can replace substances extracted using other organic solvents, which are not desirable for cosmetic purposes. The major biologically active components in $S$. baicalensis, hydrophobic baicalin and baicalein, can be extracted more easily using alkaline water rather than using ethanol.

Effect of extraction solvents on cytotoxicity The cell toxicity of each extract against human fibroblasts is shown in Fig. 1. The ethanol extract showed the highest cell toxicity of $15.6 \%$. In general, the lowest cytotoxicity was observed for extracts from alkaline water. Ethanol extracts showed the highest cytotoxicity values, even when the

Table 1. Comparison of the extraction yields of $S$. baicalensis using different extraction processes

\begin{tabular}{cc}
\hline Extraction process & Extraction yields $(\%)^{*}$ \\
\hline $\mathrm{WE}^{1)}$ & $19.2 \pm 0.48^{\mathrm{A} 4)}$ \\
$\mathrm{EE}^{2)}$ & $20.3 \pm 0.17^{\mathrm{B}}$ \\
$\mathrm{AWE}^{3)}$ & $21.8 \pm 0.56^{\mathrm{C}}$ \\
\hline
\end{tabular}

${ }^{1)} \mathrm{WE}, S$. baicalensis from water extraction at $100^{\circ} \mathrm{C}$

${ }^{2)} \mathrm{EE}, S$. baicalensis from $70 \%$ ethanol extraction at $80^{\circ} \mathrm{C}$

3) AWE, S. baicalensis from alkaline reduced water extraction at $100^{\circ} \mathrm{C}$

${ }^{4)}$ Mean values $\pm \mathrm{SD}$ from triplicate independent experiments are shown; means with different letters (A-C) within the same concentration are significantly different at $p<0.05$. 


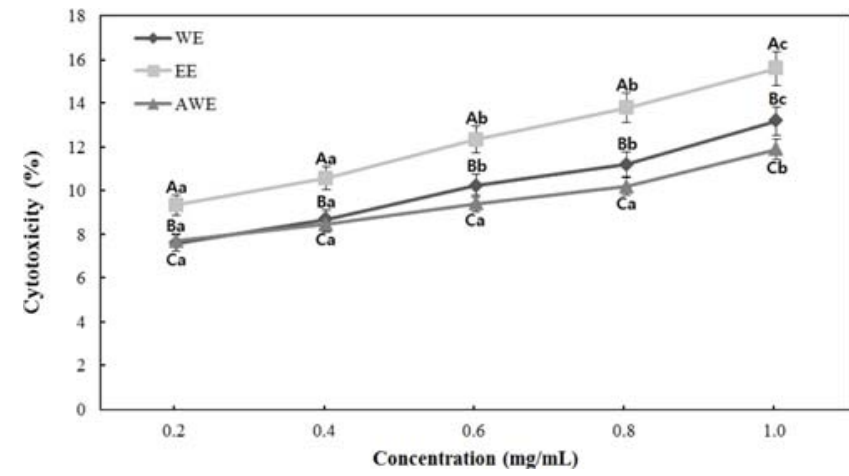

Fig. 1. Cytotoxicity of Scutellaria baicalensis extracts against human skin fibroblast CCD-986 cells under different extraction conditions. WE, S. baicalensis from water extraction at $100^{\circ} \mathrm{C}$; EE, $S$. baicalensis from $70 \%$ ethanol extraction at $80^{\circ} \mathrm{C}$; AWE, $S$. baicalensis from alkaline reduced water extraction at $100^{\circ} \mathrm{C}$; mean values $\pm \mathrm{SD}$ from triplicate independent experiments are shown; means with different letters (A-C) within the same concentration are significantly different at $p<0.05$, and means with different letters (a-c) within the same sample are significantly different at $p<0.05$.

extraction yield from ethanol was similar to the yield from alkaline water (the highest extraction yield). Thus, alkaline water eluted both hydrophobic and hydrophilic components, but lesser amounts of hydrophobic substances since more toxic hydrophobic substances were extracted using $70 \%$ ethanol. Furthermore, there were no significant differences $(p<0.05)$ between hot water and alkaline reduced water extracts, supporting the hypothesis that harmful substances were only extracted using $70 \%$ ethanol. Moreover, pure water can not be used to elute hydrophobic baicalin, which also results in a decreased biological activity of extracts using distilled water. For the anti-inflammatory activity, the low cell toxicity effect of $S$. baicalensis is an important characteristic when comparing this material to other natural substances $(22,23)$.

Measurement of antioxidant activities To verify the increased anti-inflammatory activities of $S$. baicalensis alkaline reduced water extracts, antioxidant activities were determined (Table 2). Higher antioxidant activities, based on DPPH free radical scavenging, impacted the antiinflammatory effect (24). Ascorbic acid, a positive control, had the maximum DPPH free radical scavenging activity of $80 \%$, followed by $66 \%$ for baicalein (a main component of $S$. baicalensis), $61 \%$ for alkaline reduced water extracts, $57 \%$ for $70 \%$ ethanol extracts, and $50 \%$ for hot water extracts. Baicalein is known to be a highly antioxidant fatsoluble substance, and the high DPPH radical scavenging ability of the alkaline reduced water extracts, as well as the high level of baicalein extraction, a fat-soluble extract, is believed to correspond to a high antioxidative activity. In agreement with this study, the $S$. baicalensis methanol extract reported by Kim (25) showed a higher value than
Table 2. Estimation of free radical scavenging activities of $S$. baicalensis using different extraction processes

\begin{tabular}{lc}
\hline Extraction process & $\begin{array}{c}\text { The DPPH radical } \\
\text { scavenging activity }(\%)^{*}\end{array}$ \\
\hline $\mathrm{WE}^{1)}$ & $50.28 \pm 0.31^{\mathrm{A} 6)}$ \\
$\mathrm{EE}^{2)}$ & $57.39 \pm 0.28^{\mathrm{B}}$ \\
$\mathrm{AWE}^{3)}$ & $61.06 \pm 0.38^{\mathrm{C}}$ \\
Baicalein $^{4)}$ & $66.07 \pm 0.29^{\mathrm{D}}$ \\
Ascorbic acid & $79.84 \pm 0.19^{\mathrm{E}}$ \\
\hline
\end{tabular}

${ }^{1)} \mathrm{WE}$, S. baicalensis from water extraction at $100^{\circ} \mathrm{C}$

${ }^{2)} \mathrm{EE}, S$. baicalensis from $70 \%$ ethanol extraction at $80^{\circ} \mathrm{C}$

${ }^{3)} \mathrm{AWE}, \mathrm{S}$. baicalensis from alkaline reduced water extraction at $100^{\circ} \mathrm{C}$

${ }^{4)}$ Baicalein, standard

${ }^{5)}$ Ascorbic acid, positive control

${ }^{6}$ Mean values \pm SD from triplicate independent experiments are shown; means with different letters (A-E) within the same concentration are significantly different at $p<0.05$.

the $12.5 \%$ DPPH radical scavenging activity measured at the $500 \mu \mathrm{g} / \mathrm{mL}$ concentration in this study (25). Thus, baicalein, an indicator of $S$. baicalensis and a fat-soluble substance, does not have a high antioxidative activity, even when extracted using an organic solvent. However, substances obtained from AWE of S. baicalensis demonstrated higher antioxidative activities than substances extracted using hot water ethanol. This increased antioxidative activity is attributed to a strong synergistic effect between the antioxidative activity of baicalein in S. baicalensis and the strong antioxidative activity of alkaline reduced water.

Measurement of NO production in macrophages The anti-inflammatory activity was verified by measuring NO production in mouse microphage RAW264.7 cells. The NO production ability was verified by studying $S$. baicalensis extracts obtained using different solvents and by investigating the effects of LPS treatment. Resveratrol, a positive control, and baicalein, a standard, were used to compare experimental groups.

The results of comparative NO production are shown in Fig. 2. Differences were verified by comparison of results from the resveratrol-administered group (control) with sample groups. The LPS-treated $S$. baicalensis ethanol extract group exhibited $7.12 \mu \mathrm{mol}$ nitric oxide production when using a $1.0 \mathrm{mg} / \mathrm{mL}$ extract concentration as a standard. The LPS-treated $S$. baicalensis alkaline reduced water extract exhibited a $6.71 \mu \mathrm{mol}$ nitric oxide production. The experimental group that was not treated with LPS exhibited in a high $3.92 \mu \mathrm{mol}$ NO production with the $S$. baicalensis hot water extract. NO production values for the ethanol and alkaline reduced water extracts were 3.61 and $3.25 \mu \mathrm{mol}$, respectively. Comparing nitric oxide production between the LPS-treated group and the non-LPS-treated group indicated that the $S$. baicalensis alkaline reduced water extract reduced the $6.71 \mu \mathrm{mol}$ nitric oxide production to $3.25 \mu \mathrm{mol}$, verifying a decrease in nitric oxide generation. 


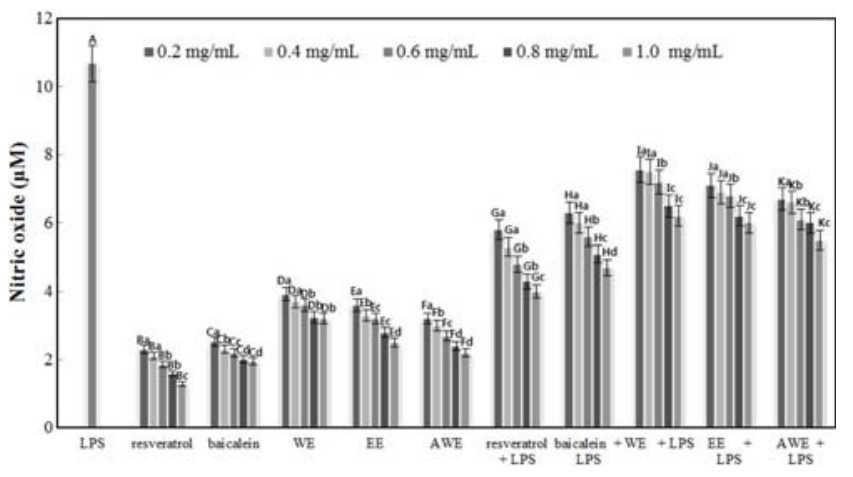

Fig. 2. Comparison of NO Production in $S$. baicalensis extracts under different extraction conditions. WE, $S$. baicalensis from water extraction at $100^{\circ} \mathrm{C}$; EE, S. baicalensis from $70 \%$ ethanol extraction at $80^{\circ} \mathrm{C}$; AWE, $S$. baicalensis from alkaline reduced water extraction at $100^{\circ} \mathrm{C}$; resveratrol, positive control; baicalein, standard;mean values $\pm \mathrm{SD}$ from triplicate independent experiments are shown; means with different letters $(A-C)$ within the same concentration are significantly different at $p<0.05$, and means with different letters (a-c) within the same sample are significantly different at $p<0.05$.

In addition, the group treated with LPS-only was compared with the group treated with LPS and the $S$. baicalensis extracted using different solvents. All experiments reduced the NO production by more than $2.4 \mu \mathrm{mol}$. Thus, the antioxidative activity of $S$. baicalensis extracted using alkaline reduced water lowered NO production to 3.25 $\mu \mathrm{mol}$, which was lower than values for the hot water and ethanol extracts. Therefore, alkaline reduced water extracts exhibited increased antioxidative effects (26-28). The strong antioxidative activities of baicalin and baicalein in $S$. baicalensis prevented the oxidative damage caused by free radicals and the skin barrier effect, and induced the skin immune reaction that substantially reduces $\mathrm{NO}$ production $(2-6,29,30)$.

Measurement of prostaglandin $\mathrm{E}_{\mathbf{2}}\left(\mathrm{PGE}_{2}\right)$ production $\mathrm{PGE}_{2}$ production was measured to determine the anti-

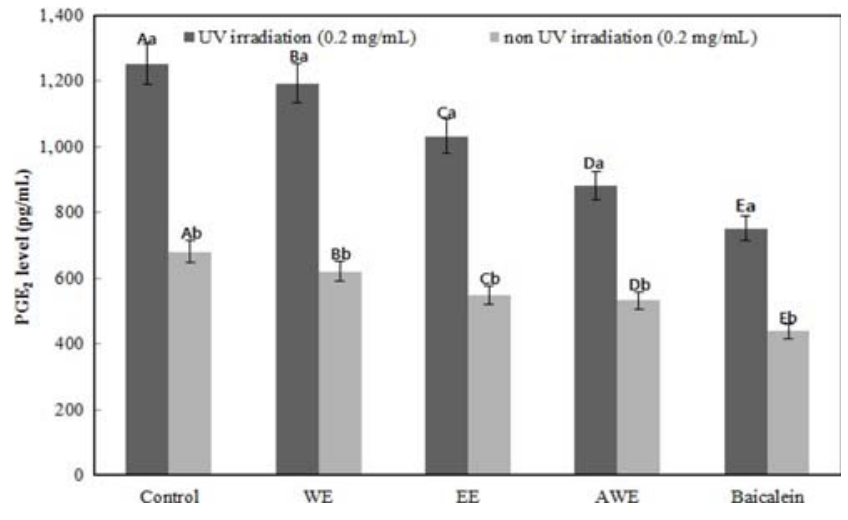

Fig. 3. Effect of $\boldsymbol{S}$. baicalensis extracts on production of $\mathrm{PGE}_{2}$ in macrophages. Control, no treatment; WE, S. baicalensis from water extraction at $100^{\circ} \mathrm{C}$; EE, S. baicalensis from $70 \%$ ethanol extraction at $80^{\circ} \mathrm{C}$; AWE, S. baicalensis from alkaline reduced water extraction at $100^{\circ} \mathrm{C}$; baicalein, standard; mean values $\pm \mathrm{SD}$ from triplicate independent experiments are shown; means with different letters (A-C) within the same concentration are significantly different at $p<0.05$, and means with different letters (a-c) within the same sample are significantly different at $p<0.05$.

inflammatory activity of $S$. baicalensis extracted using alkaline reduced water. $\mathrm{PGE}_{2}$ production showed the ability of each sample to inhibit $\mathrm{PGE}_{2}$ production. Measured $\mathrm{PGE}_{2}$ production at a low extract concentration of $0.2 \mathrm{mg} /$ $\mathrm{mL}$ is shown in Fig. 3. Measurements of $\mathrm{PGE}_{2}$ production at each concentration (based on Fig. 3) are shown in Table 3.

Activation of anti-inflammatory activity by a low alkaline reduced water extract concentration $(0.2 \mathrm{mg} / \mathrm{mL})$ resulted in $\mathrm{PGE}_{2}$ production of $881.25 \mathrm{pg} / \mathrm{mL}$ with $\mathrm{UV}$ treatment, and $532.19 \mathrm{pg} / \mathrm{mL}$ without UV treatment. Thus, reductions in $\mathrm{PGE}_{2}$ production of 370 and $150 \mathrm{pg} / \mathrm{mL}$ with and without the UV treatment, respectively, compared with controls, demonstrated the anti-inflammatory effect. In addition, the hot water extract reduced $\mathrm{PGE}_{2}$ production by 58 and 60 $\mathrm{pg} / \mathrm{mL}$ with and without UV treatment, respectively. The

Table 3. Effects of $S$. baicalensis extracts on $\mathrm{PGE}_{2}$ production in human fibroblasts with and without $\mathrm{UV}$ exposure

\begin{tabular}{lcccccc}
\hline \multirow{2}{*}{$\begin{array}{c}\text { Extraction } \\
\text { process }\end{array}$} & \multicolumn{5}{c}{ PGE $_{2}$ level } \\
\cline { 2 - 7 } & \multicolumn{1}{c}{ UV irradiated } & non-UV irradiated & UV irradiated & non-UV irradiated & UV irradiated & non-UV irradiated \\
\cline { 2 - 7 } & $0.2 \mathrm{mg} / \mathrm{mL}$ & $0.2 \mathrm{mg} / \mathrm{mL}$ & $0.6 \mathrm{mg} / \mathrm{mL}$ & $0.6 \mathrm{mg} / \mathrm{mL}$ & $1.0 \mathrm{mg} / \mathrm{mL}$ & $1.0 \mathrm{mg} / \mathrm{mL}$ \\
\hline Control $^{1)}$ & $1250.21 \pm 0.18^{\mathrm{Aa} 6)}$ & $682.17 \pm 0.18^{\mathrm{Ab}}$ & & & \\
$\mathrm{WE}^{2)}$ & $1192.19 \pm 0.18^{\mathrm{Ba}}$ & $621.41 \pm 0.25^{\mathrm{Bb}}$ & $1154.91 \pm 0.31^{\mathrm{Bc}}$ & $601.20 \pm 0.28^{\mathrm{Bd}}$ & $1115.42 \pm 0.32^{\mathrm{Be}}$ & $592.00 \pm 0.21^{\mathrm{Bf}}$ \\
$\mathrm{EE}^{3)}$ & $1032.80 \pm 0.41^{\mathrm{Ca}}$ & $548.42 \pm 0.19^{\mathrm{Cb}}$ & $981.70 \pm 0.42^{\mathrm{Cc}}$ & $542.42 \pm 0.33^{\mathrm{Cd}}$ & $942.47 \pm 0.24^{\mathrm{Ce}}$ & $532.41 \pm 0.15^{\mathrm{Cf}}$ \\
$\mathrm{AWE}^{4)}$ & $881.25 \pm 0.26^{\mathrm{Da}}$ & $532.19 \pm 0.43^{\mathrm{Db}}$ & $812.30 \pm 0.18^{\mathrm{Dc}}$ & $508.53 \pm 0.17^{\mathrm{Dd}}$ & $753.74 \pm 0.11^{\mathrm{De}}$ & $498.00 \pm 0.26^{\mathrm{Df}}$ \\
Baicalein $^{5)}$ & $752.41 \pm 0.31^{\mathrm{Ea}}$ & $439.81 \pm 0.21^{\mathrm{Eb}}$ & & & & \\
\hline
\end{tabular}

${ }^{1)}$ Control, non treatment

${ }^{2)} \mathrm{WE}, S$. baicalensis from water extraction at $100^{\circ} \mathrm{C}$

${ }^{3)} \mathrm{EE}, \mathrm{S}$. baicalensis from $70 \%$ ethanol extraction at $80^{\circ} \mathrm{C}$

${ }^{4)} \mathrm{AWE}, \mathrm{S}$. baicalensis from alkaline reduced water extraction at $100^{\circ} \mathrm{C}$

${ }^{5)}$ Baicalein, standard

${ }^{6}$ Mean values $\pm \mathrm{SD}$ from triplicate independent experiments are shown; means with different letters (A-E) within the same concentration are significantly different at $p<0.05$, and means with different letters (a-f) within the same sample are significantly different at $p<0.05$. 
ethanol extract reduced the amount of $\mathrm{PGE}_{2}$ production by 217 and $133 \mathrm{pg} / \mathrm{mL}$ with and without the UV treatment, respectively. Thus, the anti-inflammatory activity of alkaline reduced water extracts was higher than that of other extracts. However, the positive control baicalein reduced $\mathrm{PGE}_{2}$ production of the control group by 500 and $243 \mathrm{pg} /$ $\mathrm{mL}$ with and without UV treatment, respectively, the largest reductions in $\mathrm{PGE}_{2}$ production, indicating the better anti-inflammatory activity of the artificial substance baicalein. The $S$. baicalensis alkaline reduced water extract, a natural substance, showed less anti-inflammatory activity than baicalein. However, the alkaline reduced water extract showed a higher anti-inflammatory effect than the other types of extracts.

As the sample concentration increased linearly, the $\mathrm{PGE}_{2}$ production decreased (Table 3), demonstrating an increase in the anti-inflammatory activity. Without UV treatment and at the highest extract concentration of $1.0 \mathrm{mg} / \mathrm{mL}$, samples showed reductions in $\mathrm{PGE}_{2}$ production of; hot water extract, $90.17 \mathrm{pg} / \mathrm{mL}$; ethanol extract, $149.76 \mathrm{pg} / \mathrm{mL}$; alkaline reduced water extract, $184.17 \mathrm{pg} / \mathrm{mL}$; and baicalein $269.56 \mathrm{pg} / \mathrm{mL}$. The highest anti-inflammatory activity was observed for baicalein, followed by the alkaline reduced water, ethanol, and hot water extracts. Furthermore, when $\mathrm{PGE}_{2}$ production was increased using UV treatment, the hot water extract reduced $\mathrm{PGE}_{2}$ production by $134.79 \mathrm{pg} /$ $\mathrm{mL}$, the ethanol extract reduced $\mathrm{PGE}_{2}$ production by $307.74 \mathrm{pg} / \mathrm{mL}$, and the alkaline reduced water extract reduced $\mathrm{PGE}_{2}$ production by $496.47 \mathrm{pg} / \mathrm{mL}$. More obvious sample differences in the anti-inflammatory effect with UV treatment were evident than for samples not treated with UV. In addition, when $\mathrm{PGE}_{2}$ production was increased using UV stimulation, reductions in $\mathrm{PGE}_{2}$ production for extracts were $134.79 \mathrm{pg} / \mathrm{mL}$ for the hot water, $307.74 \mathrm{pg}$ / $\mathrm{mL}$ for the ethanol, and $496.47 \mathrm{pg} / \mathrm{mL}$ for the alkaline reduced water extracts, indicating the increased antiinflammatory effect of UV treatment compared with decreases without UV treatment.

These results might be attributable to a UV-induced peptide that inhibits secretion of cytokines (IL-1 and TNF) and future $\mathrm{PLA}_{2}$ activation, or to final treatment with arachidonic acid, a direct inflammatory substance that is secreted from phospholipids and is an inflammatory mediator that is generated during inflammation to accelerate skin damage (worsening of inflammatory diseases and atopic dermatitis by oxidative stress and oxidative substances). However, the anti-inflammatory effect was assumed to be increased because oxidative substances were removed by strong antioxidants, such as baicalin and baicalein in $S$. baicalensis (31). A more detailed study of the anti-skin inflammatory mechanism of extracts should be performed with consideration of RNA and protein expression levels related to anti-inflammation genes.
Comparison of extract HPLC profiles Comparison of HPLC chromatograms used to measure changes in the content of useful active ingredients obtained from different extraction methods are shown in Fig. 4. Chromatograms for baicalein (the main ingredient of $S$. baicalensis), the hot water, the $70 \%$ ethanol, and the alkaline reduced water extracts are shown in Fig. 4A-4D. In Fig. 4, S. baicalensis extraction were peaked at around the $11.2 \mathrm{~min}$ retention time, and sample of $S$. baicalensis values of 1.157, 2.215, and $8.894 \mathrm{mg} / \mathrm{g}$ were measured for $\mathrm{B}, \mathrm{C}$ and $\mathrm{D}$, respectively.

Baicalein in $S$. baicalensis is a fat-soluble substance, the content of which was expected to be highest in the $70 \%$ ethanol extract. However, the content was $8 \times$ higher in the alkaline reduced water extract, presumably due to the small size of the alkaline reduced water cluster (approximately $60 \mathrm{~Hz}$ ). This size enabled fast absorption, extraction, and solubility through the cell walls of $S$. baicalensis, thus increasing the baicalein content in alkaline reduced water
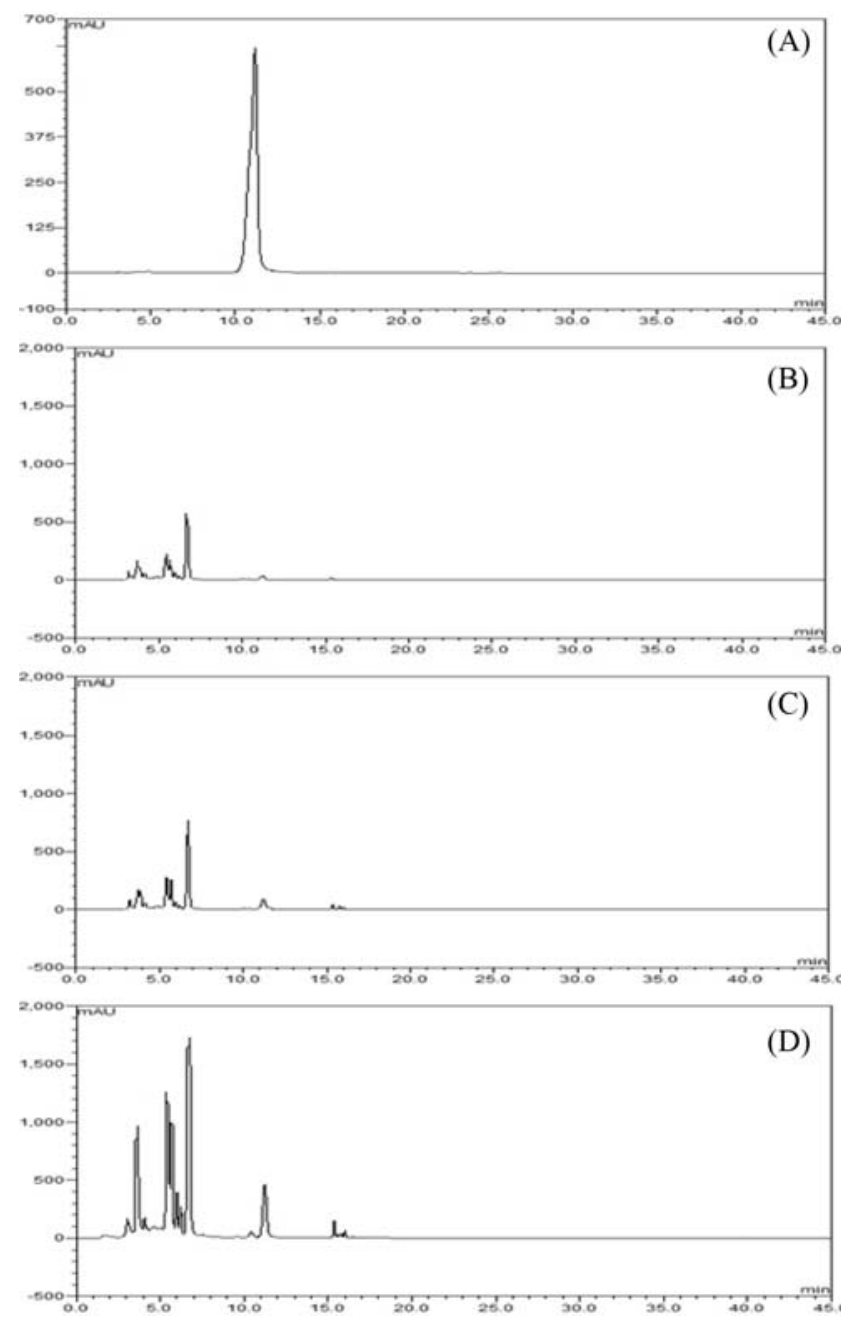

Fig. 4. Comparison of HPLC peaks of $S$. baicalensis extracts using different extraction Solvents. (A) Baicalein 100 ppmstandard; (B) $100^{\circ} \mathrm{C}$ water extracts; (C) $80^{\circ} \mathrm{C} 70 \%$ ethanol extracts; (D) $100^{\circ} \mathrm{C}$ alkaline reduced water extracts 
extracts (12). Additionally, elution of baicalein indicated that alkaline reduced water was able to extract hydrophobic substances.

Quantitative analysis using S. baicalensis 70\% methanol extracts with ultrasonic treatment was conducted to determine retention times. The time was $7.5 \mathrm{~min}$ for baicalin and 15.6 min for baicalein. S. baicalensis hot water extracts showed retention times of $7.65 \mathrm{~min}$ for baicalin and $11.65 \mathrm{~min}$ for baicalein, indicating the lower molecular weight of baicalin relative to baicalein $(32,33)$.

Baicalein, which is hydrolyzed to glucuronic acid and baicalein, had a high peak that appeared prior to the 11.2 minute peak of baicalein. This peak was due to low $\mathrm{Mw}$ flavonoids and polyphenols, including baicalin and glucuronic acid. The extract amount presumably increased due to AWE (34).

The amount of baicalein, a main bioactive substance in alkaline reduced water extracts, other minor bioactive substances, such as the low $\mathrm{M}_{\mathrm{W}}$ substances baicalin, glucuronic acid, and other molecules, They were higher than amounts from conventional WE and EE. Alkaline reduced water can be used to extract both water-soluble and fat-soluble substances. Complex substances in extracts demonstrated the synergistic effect between the activities of fat-soluble substances and water-soluble substances, which increased the skin anti-inflammatory activities of alkaline reduced water extracts, compared to hot water and $70 \%$ ethanol extracts.

Acknowledgments This study was supported by a grant of the Korean Health Technology R\&D Project, Ministry of Health \& Welfare, Republic of Korea. (Grant No. HN12C0060).

Disclosure The authors declare no conflict of interest.

\section{References}

1. Lee MJ, Oh JS, Park JW, Kim JK, Choi DY, Kim CH. Antioxidant activity of extract from Scutellaria baicalensis Georgi. J. Life. Sci. 10: 236-240 (2000)

2. Yoon HJ, Park YS. Effects of Scutellaria baicalensis water extract on lipid metabolism and antioxidant defense system in rats fed high fat diet. J. Korean Soc. Food Sci. Nutr. 39: 219-226 (2010)

3. Chi TS, Lim H, Park H, Kim HP. Effects of wogonin, a plant flavone from Scutellaria radix on skin inflammation: In vivo regulation of inflammation-associated gene expression. Biochem. Pharmacol. 66: 1271-1278 (2003)

4. Gao D, Tawa R, Masaki H, Okano Y, Sakurai H. Protective effects of baicalein against reactive oxygen species. Chem. Pharm. Bull. 46: 1383-1387 (1998)

5. Huang Y, Tsang SY, Tao X, Lau CW, Su YL, Chen ZY. Baicalein induced vascular response in rat mesenteric artery: Role of endothelial nitric oxide. Clin. Exp. Pharmacol. Physiol. 29: 721-724 (2002)

6. Kimura Y, Kubo M, Tani T, Arichi OH. Studies on Scutellariae
Radixs: Effects on lipid peroxidation in rat liver. Chem. Pharm. Bull. 29: 2610-2617 (1981)

7. Choi WK, Pi SJ, Kim NS, Woo JK, Kim KS, Cho TH. Caffeine dissolution properties of coffee beans in electrolyzed alkaline water. Korean J. Waters 1: 25-29 (2010)

8. Lee KJ. Alkaline reduced water. Funct. Waters 1: 21-26 (2010)

9. Kang SC, Seo HJ. Storage enhancement of citrus fruits by washing treatment with electrolyzed alkaline water. Life Sci. Res. 1: 149-160 (2002)

10. Choi WK. Serpentine pretreatment using electrolyzed reduced water for mineral carbonation materials. Trans Korean Hydrog. New Energy Soc. 20: 447-454 (2009)

11. Nocco PB. Mineral water as a cure. Veroff. Schweiz. Ges. Gesch. Pharm. 29: 13-402 (2008)

12. Behzadi G, Fekri L. Electrical parameter and permittivity measurement of water samples using the capacitive sensor. Int. J. Water Resour. Environ. Sci. 2 : 66-75 (2013)

13. Shirahata S, Kabayama S, Nakano M, Miura T, Kusumoto K, Gotoh M, Hayashi H, Otsubo K, Morisawa S, Katakura Y. Electrolyzedreduced water scavenges active oxygen species and protects DNA from oxidative damage. Biochem. Bioph. Res. Co. 234: 269-274 (1997)

14. Sim K, Shin H, Youn HJ, Lee HL. Isolation and purification of hemicelluloses in alkali pre-extractives from mixed hardwood. J. Korea Tech. Assoc. Pulp Pap. Ind. 42: 64-70 (2010)

15. Lee HS, Kweon MH, Lim WJ, Sung HC, Yang HC. An anticoagulant polysaccharide isolated from the alkali extracts of Coriolus versicolor. Korean J. Food Sci. Technol. 29: 369-375 (1997)

16. Lee AY, Choo BK, Chun JM, Kim HJ, Jang S, Lee HY, Kim HS. Quality monitoring of distributed herbal medicine, Scutellariae Radix. Korean J. Med. Crop Sci. 16: 150-154 (2008)

17. Kim CH, Kwon MC, Han JG, Na CS, Kwak HG, Choi GP, Park UY, Lee HY. Skin-whitening and UV-protective effects of Angelica gigas Nakai extracts on ultra high pressure extraction process. Korean J. Med. Crop Sci.16: 255-260 (2008)

18. Mosmann T. Rapid colorimetric assay for cellular growth and survival: Application to proliferation and cytotoxicity assays. J. Immunol. Methods 65: 55-63 (1983)

19. Dietz BM, Kang YH, Liu G, Eggler AL, Yao P, Chadwick LR, Pauli GF. Xanthohumol isolated from humulus lupulus inhibits menadioneinduced DNA damage through induction of quinone reductase. Chem. Res. Toxicol. 18: 1296-1305 (2005)

20. Green LC, Wagner DA, Glogowski J, Skipper PL, Wishnok JS, Tannenbaum SR. Analysis of nitrate, nitrate, and $[15 \mathrm{~N}]$ nitrate in biological fluids. Anal. Biochem. 126: 131-138 (1982)

21. Shen YC, Chiou WF, Chou YC, Chen CF. Mechanisms in mediating the anti-inflammatory effects of baicalin and baicalein in human leukocytes. Eur. J. Pharmacol. 465: 171-181 (2003)

22. Shieh DE, Liu LT, Lin CC. Antioxidant and free radical scavenging effects of baicalein, baicalin and wogonin. Anticancer Res. 20: 2861-2865 (2000)

23. Nagai H, Osuga K, Koda A. Inhibition of hypersensitivity reactions by soluble derivatives of baicalein. Jpn. J. Pharmacol. 25: 763-772 (1975)

24. Ju MJ, Do JR, Kwon JH, Kim HK. Physiological activities of mistletoe extracts from Viscum album L. J. Korean Soc. Food Sci. Nutr. 38: 529-534 (2009)

25. Kim SC, Ahn KS, Park CK, Jeon BS, Lee JT, Park WJ. Isolation of antioxidative compound from Scutellaria baicalensis G. Korean J. Med. Crop Sci. 14: 212-216 (2006)

26. Lin YL, Lin JK. (-)-Epigallocatechin-3-gallate blocks the induction of nitric oxide synthase by down-regulating lipopolysaccharideinduced activity of transcription factor nuclear factor-kappaB. Mol. Pharmacol. 52: 465-472 (1997)

27. Tsai SH, Lin-Shiau SY, Lin JK. Suppression of nitric oxide synthase and the down-regulation of the activation of NF kappaB in macrophages by resveratrol. Brit. J. Pharmacol. 126: 673-680 (1999)

28. Liang YC, Huang YT, Tsai SH, Lin-Shiau SY, Chen CF, Lin JK. Suppression of inducible cyclooxygenase and inducible nitric oxide synthase by apigenin and related flavonoids in mouse macrophages. 
Carcinogenesis 20: 1945-1952 (1999)

29. Wright RJ. Stress and atopic disorders. J. Allergy Clin. Immunol. 116: 1301-1306 (2005)

30. Heo JH, Song HN, Jang SI. Effects of gagambojungikgi-tang on the immune mediators regulation and wound healing in the rsj26 or chemical antigen induced atopic dermatitis model mice. Korean J. Herbol. 23: 53-61 (2008)

31. Lee DJ, Jeon IH, Kim HS, Cho IY, Jang SI. Antioxidative and antiinflammatory effect of ethanol extract from duchesneachrysantha. Kor. J. Ori. Physiol. Pathol. 26: 59-66 (2012)

32. Lai MY, Chen CC, Hsiu SL, Chao PD. Analysis and comparison of baicalin, baicalein and wogonin contents in traditional decoctions and commercial extracts of Scutellariae Radix. J. Food Drug Anal. 9: 145-149 (2001)

33. Rhee JS, Woo ER, Kim NH, Lee EJ, An DK, Lee JH, Park SK, Park HK. A Study on qualitative and quantitative analysis of major ingredients in Scutellariae radix. J. Anal. Sci. Technol. 10: 91-104 (1997)

34. Tomimori T, Jin H, Miyaichi Y, Toyofuku S, Namba T. Quantitative analysis of flavonoids in Scutellaria roots by high-performance liquid chromatography. J. Pharm. Soc. Jpn. 105: 148-155 (1985) 